\title{
SYNTHESIS OF Cu@ZnO CORE-SHELL NANOPARTICLES BY SPARK DISCHARGES IN LIQUID NITROGEN
}

\author{
H. Kabbara ${ }^{1}$, J. Ghanbaja ${ }^{1}$, C. Noëe ${ }^{1,2}$, T. Belmonte ${ }^{1,2, *}$ \\ ${ }^{1}$ Université de Lorraine, Institut Jean Lamour, UMR CNRS 7198, NANCY, F-54042, France \\ ${ }^{2}$ CNRS, Institut Jean Lamour, UMR CNRS 7198, NANCY, F-54042, France \\ * corresponding author. Email: thierry.belmonte@univ-lorraine.fr
}

PACS number: $52.80 . \mathrm{Wq}$ Discharge in liquids and solids

Keywords: Spark discharges ; submerged discharges ; Core-shell structures ; Nanostructures ;

Time-resolved optical emission spectroscopy 


\section{ABSTRACT}

Core-shell nanoparticles are synthesized by nanosecond-pulsed discharges in liquid nitrogen using a two-step process. In a first step, copper nanoparticles (resp. zinc nanosheets) are synthesized by eroding pure copper (resp. zinc) electrodes. In a second step, copper (resp. zinc) electrodes are removed and replaced by zinc (resp. copper) electrodes in the liquid loaded with copper nanoparticles (resp. zinc nanosheets). After erosion and air oxidation, once nitrogen has evaporated, $\mathrm{Cu} @ \mathrm{ZnO}$ core-shell nanoparticles are obtained in both configurations. The shell is always $\mathrm{ZnO}$, because of the unusual formation of zinc nanosheets instead of zinc nanoparticles. When $\mathrm{Cu}$ electrodes are used first, copper nanoparticles are wrapped in $\mathrm{ZnO}$ nanosheets. When $\mathrm{Zn}$ electrodes are used first, copper nanoparticles hit zinc nanosheets and get coated to form also $\mathrm{Cu} @ \mathrm{ZnO}$. In this latter case, $\mathrm{Cu}_{2} \mathrm{O} @ \mathrm{ZnO}$ are sometimes encountered too but to a much lesser extent. Copper oxidation is then attributed to a failure in the zinc protective shell. Time-resolved optical emission spectroscopy measurements reveal that $\mathrm{Cu}$ lines and $\mathrm{Zn}$ lines are never emitted simultaneously, the element in the liquid remaining outside the discharge area. If zinc nanosheets are synthesized first, $\mathrm{N}$ II lines are exclusively observed during the first $200 \mathrm{~ns}$ of discharges with copper electrodes, revealing for this process the possibility of highly energetic processes. 


\section{INTRODUCTION}

Synthesis of nanoparticles (NPs) by discharges in dielectric liquids is an efficient way to process nanostructures at high rate and very low cost [1]. $\mathrm{ZnO}$ and $\mathrm{CuO}$ are semiconductors that are extensively studied. They both present an appreciable photocatalytic activity and might be good candidates for photocatalysis and solar cells [2-4]. They also offer perspectives in sensing applications [5-7]. Their band gaps are $\sim 3.3 \mathrm{eV}, 1.2-1.9 \mathrm{eV}$ and $\sim 2.3$ $\mathrm{eV}$ for $\mathrm{ZnO}$ (intrinsic n-type), $\mathrm{CuO}$ (intrinsic p-type) and $\mathrm{Cu}_{2} \mathrm{O}$ (intrinsic p-type) respectively. On the contrary, the $\mathrm{CuO}-\mathrm{ZnO}$ system has thus far received little attention. The mixed systems of zinc oxide and copper oxide as nanosize core-shell structures have only been reported by Tamanis et al. [8] very recently. Furthermore, $\mathrm{Cu} @ \mathrm{ZnO}$ core-shell nanostructures have been acknowledged to be important catalysts for methanol production from synthesis gas at moderate pressures and temperatures $[9,10]$.

If the synthesis of copper oxides and zinc oxide NPs by discharges in liquids have been amply investigated [11-16], the same is not true for core-shell structures and alloys. Panuthai et al. [17] eroded copper-zinc $(\mathrm{Cu}-\mathrm{Zn})$ alloy electrodes with different copper contents $(90 \mathrm{Cu} / 10 \mathrm{Zn}$ and $65 \mathrm{Cu} / 35 \mathrm{Zn}$ ) by an arc discharge submerged in glycol, ethanol and deionized water. They could produce a mixture of $\mathrm{Cu}, \mathrm{Cu}-\mathrm{Zn}$, and zinc oxide nanoparticles with size distributions

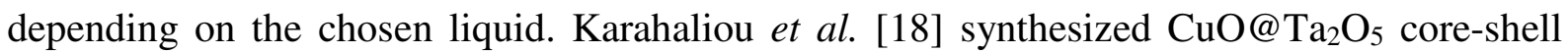
NPs by anodic arc-discharges in water. They run discharges between a graphite electrode and a U-shaped circular stainless steel holder filled with compressed copper and tantalum micrograins. According to these authors, in the specific arrangement used, mechanisms involved in the synthesis of $\mathrm{CuO} @ \mathrm{Ta}_{2} \mathrm{O}_{5} \mathrm{NPs}$ are unknown.

In the present work, we study the possibility to grow core-shell nanoparticles in the $\mathrm{Cu}-\mathrm{Zn}-\mathrm{O}$ system by discharges in liquid nitrogen via a three-step process. Discharges are run first between two copper electrodes to produce Cu NPs. Next, new discharges are run between two zinc electrodes in the same liquid where Cu NPs, formed during the first step, are present. 
$\mathrm{Cu} @ \mathrm{Zn}$ core-shell NPs are thus expected to be obtained, zinc coating then copper nanoparticles. To get $\mathrm{Zn@Cu} \mathrm{NPs,} \mathrm{steps} 1$ and 2 should just be swapped, but it turns out that things are more complex in this case and that will be described hereinafter. The last step corresponds to the oxidation of the synthesized core-shell NPs, which occurs after evaporation of liquid nitrogen, which leads to air exposure and transformation of metals into oxides. Besides thorough investigations of as-formed nanoparticles by different diagnostics, we resorted to time-resolved optical emission spectroscopy at the nanosecond scale to clarify the growth mechanisms of these nanostructures.

\section{EXPERIMENTAL SET-UP}

The experimental set-up was presented in detail in reference [19]. Briefly, a pin-to-pin electrode configuration was used. Electrodes were copper or zinc wires ( $1 \mathrm{~mm}$ in diameter). A high DC voltage power supply (Technix SR15-R-1200-15 kV-80 mA) fed a solid-state switch (HTS-301-03-GSM) connected to one pin-electrode, the other electrode being grounded. The voltage rise time was $20 \mathrm{~ns}$ without ballast resistor.

Experiments were run in two steps. The first step corresponds to the synthesis of one specific type of nanoparticles, say copper, in liquid nitrogen, which is known to be inert in our conditions. The experimental conditions retained here are an applied voltage of $+10 \mathrm{kV}$ and an inter-electrode gap distance of $100 \mu \mathrm{m}$. After the dielectric liquid is enriched with nanoparticles (i.e. after about one hour of successive discharges ignited at $10 \mathrm{~Hz}$ ), the second step starts. It consists in running discharges in the same liquid, now loaded in copper nanoparticles, but with two electrodes made of zinc to get a $\mathrm{Cu} @ \mathrm{Zn}$ core-shell structure. The duration of a single discharge pulse is $200 \mathrm{~ns}$. The duration of the second step of NPs synthesis process is also about one hour. The volume of the liquid used in the reactor is 100 $\mathrm{cm}^{3}$.

Nanoparticles are collected by sedimentation on a silicon wafer located under the pinelectrodes. We resorted to scanning electron microscopy (SEM) - XL30S-FEG by Philips — 
for structural and chemical observations. An EDXS (Energy-Dispersive X-ray Spectrometer) was used for elemental analysis and a TLD detector (through the lens detector) was used for high resolution imaging. A Philips CM200 device and a JEOL ARM 200F Cold FEG device were used for TEM investigation in order to study the crystallinity and the chemical composition of NPs. Electron Energy Loss Spectroscopy EELS experiments were performed in diffraction mode. The spectrometer is set to an energy dispersion $0.05 \mathrm{eV} /$ channel. Thecondenser aperture, spectrometer entrance, camera length were respectively $150 \mu \mathrm{m}, 2.5$ $\mathrm{mm}$ and $4 \mathrm{~cm}$ leading to a collection half angle of $20 \mathrm{mrad}$ and an energy resolution of $0.5 \mathrm{eV}$ measured at full width at half maximum (FWHM) of zero loss peak. Energy-Filtered Transmission Electron Microscopy (EFTEM) were recorded in STEM mode.

Optical emission spectroscopy was performed with a $550 \mathrm{~mm}$ focal length monochromator (Jobin-Yvon TRIAX 550) equipped with a $100 \mathrm{~g} \mathrm{~mm}^{-1}$ grating for overall spectra in the (250-900 nm) visible range, lines being strongly broadened and high spectral resolution useless. It was coupled with a HORIBA Jobin-Yvon i-Spectrum Two iCCD detector. Each measurement is averaged over 50 spectra recorded with an exposure time of $50 \mathrm{~ns}$. Although discharges in dielectric liquids are known to be stochastic, using a solid-state switch with a 20-ns rise time ensures a high level of reproducibility because breakdown necessarily occurs within a time window inferior to the exposure time (see reference [20] for further details). However, because of the generation of high-frequency signals by discharge current oscillations (at about $1 \mathrm{MHz}$ ), ghost lines are sometimes observed. They are easily identified in time-resolved data, for they disappear from one spectrum to the other.

\section{RESULTS AND DISCUSSION}

\subsection{On the specificity of $\mathrm{Zn}$ erosion}

If eroding copper electrodes under the chosen conditions leads to the synthesis of NPs with spherical shapes (Fig. 1a), eroding zinc electrodes gives mainly 2-dimensional nanostructures 
(nanosheets) with few spread NPs (Fig. 1b). Typically, their thickness is about $4 \mathrm{~nm}$, according to AFM measurements. Spherical NPs are made of $\mathrm{CuO}$, since copper NPs are exposed to air before TEM analysis, once liquid nitrogen has fully evaporated. These primary NPs have sizes ranging typically between 2 and $10 \mathrm{~nm}$. However, larger primary NPs, with diameters closer to $30-50 \mathrm{~nm}$ are also present, but to a lesser extent. Similarly, nanosheets are made of $\mathrm{ZnO}$. Unreported diffraction patterns and micro-EDX analyses prove undoubtedly that both metals are oxidized as $\mathrm{CuO}$ and $\mathrm{ZnO}$ respectively.

The behaviour of zinc is uncommon for a metal eroded by spark discharges in liquids. This is likely due to the use of liquid nitrogen as liquid dielectric. Indeed, all processes of the same kind are usually operated in deionized water, leading to spherical or elongated nanoparticles $[12,15]$. We assume that the synthesis of zinc nanosheets proceeds by a kind of exfoliation mechanism where a few atomic layers are detached from zinc grains submitted to the plasma flux. This mechanism would be driven by the specific structure of the zinc wire used as electrode as soon as sufficiently large thermal gradients are at stake. However, till now, no clear explanation dealing with the synthesis mechanism of these nanosheets can be put forward. Ongoing new experiments will maybe give a better understanding. Nevertheless, the specific nanosheet structure of zinc produced by plasma erosion of the electrodes is a key feature in the present work to explain how core-shell structures are formed, as described below.

\subsection{Starting with copper electrodes}

When copper nanoparticles, like those depicted in Fig. 1a, are synthesized first, a large part of these particles - i.e. those floating in the vicinity of the inter-electrode gap each time the discharge is ignited - get coated by zinc during the second step of the process. They represent about $35 \pm 5$ percent of the objects collected on a TEM grid. These NPs are then exposed to air, once liquid nitrogen is evaporated, and get oxidized. In Fig. 2a, a TEM overview of the core-shell NPs is depicted. Spherical NPs (Fig. 2a), similar to those obtained for pure copper 
(Fig. 1a), are visible. When we zoom in, we observed that these NPs are coated by a shell, which is very clear in Fig. 2b. The diffraction pattern corresponding to the selected area (Figs. 2c and 2d) indicates the presence of pure copper and zinc oxide $\mathrm{ZnO}$. We readily infer that the zinc shell protects the copper core from oxidation, once the nanostructure is put in the air. Zinc is turned into zinc oxide, which passivates the nanostructure and preserves its metallic core. On the other hand, the metallic character of the core could be confirmed by Electron Energy Loss Spectroscopy (Fig. 3). In Fig. 3a, the near-edge structure of $\mathrm{L}_{23}-\mathrm{Cu}$ in the EELS spectrum is formally identical to metallic copper's (after data available in references [21-23]). On the other hand, the near-edge structure of $\mathrm{L}_{3}-\mathrm{Zn}$ in the EELS spectrum (Fig. 3b) exhibits the same $\mathrm{P}_{1}$ and $\mathrm{P}_{2}$ contributions - due the fact that the electron beam changes from parallel to perpendicular to c-axis - as in $\mathrm{ZnO}$. Finally, running discharges between zinc electrodes in liquid nitrogen loaded with copper nanoparticles does produce $\mathrm{Cu} @ \mathrm{ZnO}$ core-shell nanostructures.

\subsection{Starting with zinc electrodes}

When zinc sheets, as those depicted in Fig. 1b, are synthesized first, they are hit by copper NPs synthesized during the second step of the process and exiting the discharge. Then, the general sheet-like aspect of zinc is kept, as it is visible in Fig. 4a. Two types of core-shell NPs are produced: $\mathrm{Cu} @ \mathrm{ZnO}\left(\sim 80-90 \%\right.$ of core-shell objects) and $\mathrm{Cu}_{2} \mathrm{O} @ \mathrm{ZnO}(\sim 10-20 \%)$.

Copper NPs synthesized in the discharge hit the zinc sheets at high speed and stick to them and/or get wrapped by zinc. Two situations arise.

First, a copper NP is fully covered by a zinc sheet. High-resolution TEM images (Fig. 4b) clearly show the full coverage of copper by zinc. The diffraction pattern corresponding to the selected area (Figs. $\mathbf{4 c}$ and $\mathbf{4 d}$ ) indicates the presence of $\mathrm{Cu}$ and $\mathrm{ZnO}$. The metallic character of the core was again confirmed by Electron Energy Loss Spectroscopy (Fig. 5). In Fig. 5a, the near-edge structure of $\mathrm{L}_{23}-\mathrm{Cu}$ in the EELS spectrum is formally identical to metallic copper's [21-23]. The near-edge structure of $\mathrm{L}_{3}-\mathrm{Zn}$ in the EELS spectrum (Fig. 5b) exhibits 
the same features as those of zinc oxide. Finally, EDXS line scanning profiles along $\mathrm{Cu} @ \mathrm{ZnO}$ core-shell nanoparticles are provided as supplemental material 1.

Second, images made by Energy-Filtered Transmission Electron Microscopy (EFTEM) of a large $\mathrm{Cu}_{2} \mathrm{O} @ \mathrm{ZnO} \mathrm{NP}$ (Figs. 6a to 6d) stress the possible presence of defects in the structure of the shell. The circled area (Fig. 6a) shows nanopores in the zinc shell. The diffraction pattern (Figs. 7b and 7c) corresponding to this core-shell object (Fig. 7a) indicates the presence of $\mathrm{Cu}_{2} \mathrm{O}$ and $\mathrm{ZnO}$. This time, copper is partly oxidized under the form of cuprous oxide. The fact that it is not fully oxidized in air, contrary to $\mathrm{Cu}$ nanoparticles that are transformed into $\mathrm{CuO}$ when no zinc is present - see Fig. 1a - is presumably due to the imperfect coverage by the $\mathrm{ZnO}$ shell that limits oxygen penetration into the NP core. Protection provided by the zinc shell is patently less efficient as in the former case. Indeed, when a large nanoparticle is observed, the zinc shell is found to be non-uniform. Its thickness varies, as might be expected, from the side where the copper NP hits the zinc sheet to the opposite side, where the contact with zinc is very limited, if not non-existent. There, the zinc shell is not continuous and exhibits open pores (see the circled region in Fig. 7a). When oxidation occurs, we presume that copper gets oxidized till $\mathrm{ZnO}$ seals the pores thanks to its molar volume $\left(14.52 \mathrm{~cm}^{3} \mathrm{~mol}^{-1}\right)$ which is one and a half time as big as zinc $\left(9.16 \mathrm{~cm}^{3} \mathrm{~mol}^{-1}\right)$. Thus, $\mathrm{Cu}_{2} \mathrm{O}$ is formed instead of $\mathrm{CuO}$. A schematic of the synthesis mechanisms for the synthesis of core-shell NPs is proposed in Fig. 8. Syntheses are reproducible with a satisfactory level, leading to very similar features as far as we could evaluate it by TEM analyses. Core-shell nanostructures did not exhibit any ageing effects after exposure to air and moisture for several weeks.

\subsection{Time-resolved optical emission spectroscopy}

Time-resolved optical emission spectroscopy was used to better understand how these coreshell NPs were synthesized. In Fig. 9a, time-resolved optical emission spectra of discharges 
between zinc electrodes, immersed in liquid nitrogen loaded in copper, are depicted. Copper loading is achieved by running $\sim 18,000$ discharges $(30 \mathrm{~min}$ at $10 \mathrm{~Hz}$ ) with the copper electrodes and by replacing them by zinc electrodes, as done in the two-step synthesis process of $\mathrm{Cu} @ \mathrm{Zn}$ core-shell NPs. We observe an intense background emission followed by the emergence of zinc emission lines when the medium cools down and becomes optically thin. The intensity of the background emission is not given in Fig. 10a, but from raw data, we know it is the highest intensity observed during the process (in our condition, it reaches 55,000 counts at the wavelength at which the grating is blazed, i.e. $500 \mathrm{~nm}$, after $150 \mathrm{~ns}$, versus a tenth of this value for the zinc transition at $481.05 \mathrm{~nm}$ after $500 \mathrm{~ns}$ ). The lack of copper lines, even though copper nanoparticles are present in liquid nitrogen, is likely due to the hindrance of an inward flux from the liquid phase by the huge pressure exerted from the core of the spark discharge outwards. The presence of intense background emission (mainly due to electron-ion recombination after [24]) at the beginning of the process masks most the lines that pop up in the spectrum after 200-250 ns typically.

In Fig. 9b, time-resolved optical emission spectra of discharges between copper electrodes immersed in liquid nitrogen loaded in zinc ( 18,000 discharges) are depicted. As explained previously, because of the very limited background emission, lines appear immediately. The most surprising result is the presence of $\mathrm{N}$ II lines (i.e. emitted by excited $\mathrm{N}^{+}$states) at short times, from 0 to $250 \mathrm{~ns}$, without any simultaneous emission of $\mathrm{N} \mathrm{I}$ or $\mathrm{N}_{2}$ I lines. The most intense atomic lines of nitrogen are known to be in the NIR spectral region [25]. Data recorded from $650 \mathrm{~nm}$ and $800 \mathrm{~nm}$ show only a very weak broad line (between 100 and 300 ns) centred at $\sim 745 \mathrm{~nm}$, which is more likely due to the N II transition expected at 745.095 $\mathrm{nm}$. New experiments would be necessary to investigate possible N I transitions beyond 800 nm.. Here again, we notice that no line of the metal which liquid nitrogen is loaded with, i.e. zinc in this case, is detected. The same argument, i.e. the expansion of the plasma that would limit the influx of zinc, can be put forward to explain this behaviour. Copper lines are 
observed after $200 \mathrm{~ns}$. A detailed analysis of all transitions observed is given as supplemental material 2.

N II lines are observed in highly-energetic discharges like lightening events or high current pulsed arcs [26, 27]. Indeed, producing $\mathrm{N}^{+*}$ excited states requires at least $24.296 \mathrm{eV}$ [28], which is the energy necessary for dissociative ionization of $\mathrm{N}_{2}$ by electron collision. However, this value is probably overestimated in media where pressure can reach several thousand bars. Indeed, the lowering of the ionization energy can be significant, leading to much lower values. As neither $\mathrm{N}$ I nor $\mathrm{N}_{2}$ I transitions are observed, we infer that these states are weakly populated and/or trapped in this optically thick medium. This observation might also result from a low concentration of one metal element with respect to the other.

The weak background emission observed in this situation suggests that the electron-ion recombination process is limited, which might be due either to a lower concentration of charged species or to an increase in the electron temperature as the cross-section of this process is favoured at low energy.

Since zinc NPs exhibit a specific sheet-like shape, we wondered whether this feature could play a role on the behaviour of discharges. Then, we used brass $(63 \mathrm{wt} . \% \mathrm{Cu}-37 \mathrm{wt} . \% \mathrm{Zn})$ electrodes instead of zinc electrodes during the first step of the process. In this case, and in order to keep the size of this paper reasonable, we will admit that spherical $\mathrm{Cu}$ and $\mathrm{Zn}$ primary NPs with size distributions below $10 \mathrm{~nm}$ are synthesized. The almost perfect overlap of spectra recorded when zinc or brass electrodes (Fig. 10) are used shows the non-influence of the shape of Zn NPs. It also shows that copper NPs do not interfere in the excitation process of N II lines.

In any situation $(\mathrm{Zn} @ \mathrm{Cu}$ or $\mathrm{Cu} @ \mathrm{Zn}), \mathrm{Cu}$ and $\mathrm{Zn}$ lines are never observed simultaneously. The metal-containing discharge made by erosion of the electrodes remains clear of metallic NPs initially contained in the dielectric liquid. This means that the synthesis of core-shell NPs occurs in post-discharge. Two steps are then required: one to produce NPs in discharge and 
one to coat them in post-discharge. Until now, no information is available on the way the transition from one step to the other occurs. New experiments are needed to better understand this transition.

\section{CONCLUSION}

We showed that $\mathrm{Cu} @ \mathrm{Zn}$ core-shell NPs are synthesized by a two-step process, whichever step is processed first. Nevertheless, the zinc shell has not the same feature, which gives, after air oxidation, either $\mathrm{Cu} @ \mathrm{ZnO}$ or $\mathrm{Cu}_{2} \mathrm{O} @ \mathrm{ZnO}$ nanostructures. This possibility is mainly due to the formation of zinc nanosheets, an uncommon shape in this kind of process that usually produces spherical nanoparticles, like for copper. The formation mechanism of these 2D nanostructures is a major stake and it is still under investigation to be fully clarified. From time-resolved optical emission spectroscopy, we found out that copper and zinc never emit lines at the same time. No alloying is then possible in these conditions. That is why core-shell structures are found. When liquid nitrogen is loaded with $\mathrm{Cu}$ NPs, only zinc lines are emitted. On the other hand, when liquid nitrogen is loaded with Zn nanosheets or NPs, N II lines are emitted during the first $200 \mathrm{~ns}$ before copper lines become visible. This process is observed here for the first time and remains unclear but it might be useful to better understand processes in dielectric liquids submitted to high voltages. 


\section{REFERENCES}

[1] T Belmonte, A Hamdan, F Kosior, C Noël, G Henrion, Interaction of discharges with electrode surfaces in dielectric liquids: application to nanoparticle synthesis, J. Phys. D: Appl. Phys. 47 (2014) 224016

[2] T. Soejima, K. Takada, S. Ito, Alkaline vapor oxidation synthesis and electrocatalytic activity toward glucose oxidation of $\mathrm{CuO} / \mathrm{ZnO}$ composite nanoarrays, Appl. Surf. Sci. 277 (2013) 192-200

[3] P. Sathishkumar, R. Sweena, J. J. Wu, S. Anandan, Synthesis of CuO-ZnO nanophotocatalyst for visible light assisted degradation of a textile dye in aqueous solution, Chem. Engin. J., 171 (2011) 136-140

[4] Z. Liu, H. Bai, S. Xu, D. D. Sun, Hierarchical CuO-ZnO "corn-like" architecture for photocatalytic hydrogen generation, Int. J. Hydrogen Energy, 36 (2011) 13473-13480

[5] L. Wang, Y. Kang, Y. Wang, B. Zhu, S. Zhang, W. Huang, S. Wang, CuO nanoparticle decorated $\mathrm{ZnO}$ nanorod sensor for low-temperature $\mathrm{H}_{2} \mathrm{~S}$ detection, Mater. Sci. Engin. C, 32 (2012) 2079-2085

[6] S. J. Kim, C. W. Na, I. S. Hwang, J. H. Lee, One-pot hydrothermal synthesis of CuO$\mathrm{ZnO}$ composite hollow spheres for selective $\mathrm{H}_{2} \mathrm{~S}$ detection, Sens. Actuators B: Chem., 168 (2012) 83-89

[7] Q. Qi, T. Zhang, Y. Zeng, H. Yang, Humidity sensing properties of $\mathrm{KCl}$ doped $\mathrm{Cu}-$ Zn/CuO-ZnO nanoparticles, Sens. Actuators B: Chem., 137 (2009) 21-26

[8] E. Tamanis, E. Sledevskis, A. Ogurcovs, Synthesis of Core/Shell CuO-ZnO Nanoparticles and Their Second-Harmonic Generation Performance, Latvian J. Phys. Techn. Sci., 52 (2015) 41-46

[9] M. Schur, B. Bems, A. Dassenoy, I. Kassatkine, J. Urban, H. Wilmes, O. Hinrichsen, M. Muhler, R. Schlögl,. Continuous coprecipitation of catalysts in a micromixer: 
Nanostructured $\mathrm{Cu} / \mathrm{ZnO}$ composite for the synthesis of methanol. Angewandte Chemie International Edition, 42 (2003) 3815-3817

[10] S.B. Kalidindi, B.R. Jagirdar, S.B. Kalidindi, B.R. Jagirdar, Synthesis of Cu@ZnO coreshell nanocomposite through digestive ripening of $\mathrm{Cu}$ and $\mathrm{Zn}$ nanoparticles, J. Phys. Chem. C, 112 (2008) 4042-8.

[11] V. S. Burakov, E. A. Nevar, M. I. Nedel'ko, N. V. Tarasenko, Synthesis and Modification of Molecular Nanoparticles in Electrical Discharge Plasma in Liquids, Russ. J. Gen. Chem., 85 (2015) 1222-1237

[12] N. Tarasenko, A. Nevar, M. Nedelko, Properties of zinc-oxide nanoparticles synthesized by electrical-discharge technique in liquids, Phys. Status Solidi A, 207 (2010) 2319-2322

[13] Chih-Hung Loa, Tsing-Tshih Tsunga, Liang-Chia Chen, Shape-controlled synthesis of Cu-based nanofluid using submerged arc nanoparticle synthesis system (SANSS), J. Cryst. Growth 277 (2005) 636-642

[14] W. T. Yao, S. H. Yu, Y. Zhou, J. Jiang, Q. S. Wu, L. Zhang, Formation of uniform CuO nanorods by spontaneous aggregation: Selective synthesis of $\mathrm{CuO}, \mathrm{Cu}_{2} \mathrm{O}$, and $\mathrm{Cu}$ nanoparticles by a solid-liquid phase arc discharge process, J. Phys. Chem. B 109 (2005) $14011-14016$

[15] A. A. Ashkarran, S. M. Mahdavi, M. M. Ahadian, Photocatalytic activity of ZnO nanoparticles prepared via submerged arc discharge method, Appl. Phys. A, 100 (2010) $1097-1102$

[16] C. H. Lo, T. T. Tsung, L. C. Chen, C. H. Su, H. M. Lin, Fabrication of copper oxide nanofluid using submerged arc nanoparticle synthesis system (SANSS), J. Nanopart. Res., 7 (2005) 313-320 
[17] N. Panuthai, R. Savanglaa, P. Praserthdam, S. Kheawhom, Characterization of copperzinc nanoparticles synthesized via submerged arc discharge with successive reduction process, Jap. J. Appl. Phys. 53 (2014) 05HA11

[18] P. K. Karahaliou, P. Svarnas, S. N. Georga, N. I. Xanthopoulos, D. Delaportas, C. A. Krontiras, I. Alexandrou, $\mathrm{CuO} / \mathrm{Ta}_{2} \mathrm{O}_{5}$ core/shell nanoparticles synthesized in immersed arc-discharge: production conditions and dielectric response, J. Nanopart. Res. 14 (2012) 1297

[19] A. Hamdan, C. Noel, F. Kosior, G. Henrion, T. Belmonte, Impacts created on various materials by micro-discharges in heptane: Influence of the dissipated charge, J. Appl. Phys. 113 (2013) 043301

[20] A. Hamdan, C. Noël, J. Ghanbaja, T. Belmonte, Comparison of Aluminium Nanostructures Created by Discharges in Various Dielectric Liquids, Plasma Chem. Plasma Process. 34 (2014) 1101-1114

[21] R.D. Leapman, L.A. Grunes, P.L. Fejes, Study of the $\mathrm{L}_{23}$ edges in the $3 d$ transition metals and their oxides by electron-energy-loss spectroscopy with comparisons to theory, Phys. Rev. B. 26 (1982) 614-635

[22] P. Ewels, T. Sikora, V. Serin, C. P. Ewels, L. Lajaunie, A Complete Overhaul of the Electron Energy-Loss Spectroscopy and X-Ray Absorption Spectroscopy Database: eelsdb.eu., Microscopy and Microanalysis, available on CJO2016. doi:10.1017/S1431927616000179.

[23] F. Hofer, P. Golob, New examples for near-edge fine structures in electron energy loss spectroscopy, Ultramicroscopy 21 (1987) 379-384

[24] A. Hamdan, C. Noël, J. Ghanbaja, T. Belmonte, Comparison of Aluminium Nanostructures Created by Discharges in Various Dielectric Liquids, Plasma Chem. Plasma Process. 34 (2014) 1101-1114 
[25] S. J. Northway, R. M. Brown, R. C. Fry, Atomic nitrogen spectra in the argon inductively coupled plasma (ICP), Appl. Spectrosc. 34 (1980) 338-348

[26] R. E. Orville, A high-speed time-resolved spectrscopic study of the lightning return stroke: Part II. A quantitative analysis, J. Atmos. Sci. 25 (1968) 839-851

[27] R. Sousa Martins, C. Zaepffel, L. Chemartin, Ph. Lalande, A. Soufiani, Characterization of a high current pulsed arc using optical emission spectroscopy, J. Phys. D: Appl. Phys. 49 (2016) 415205

[28] R. Locht, J. Schopman, H. Wankenne, J. Momigny, The dissociative ionization of nitrogen, Chemical Physics 7 (1975) 393-404 


\section{CAPTIONS}

Figure 1: a) Copper oxide $(\mathrm{CuO})$ nanoparticles synthesized between two $\mathrm{Cu}$ electrodes immerged in liquid nitrogen and observed after air exposure at different scales by TEM. b) Zinc oxide $(\mathrm{ZnO})$ sheets and nanoparticles synthesized between two $\mathrm{Zn}$ electrodes immerged in liquid nitrogen and observed after air exposure at different scales by TEM.

Figure 2: a) TEM overview of $\mathrm{Cu} @ \mathrm{ZnO}$ core-shell NPs. b) High-resolution TEM image showing the $\mathrm{ZnO}$ shell and the $\mathrm{Cu}$ core. c) Identification of hkl planes corresponding to spots 1 to 9 shown in the diffraction pattern d).

Figure 3: a) Electron Energy Loss Spectroscopy near-edge fine structures for the $\mathrm{Cu} \mathrm{L}_{23}$. b) Electron Energy Loss Spectroscopy near-edge fine structures for the $\mathrm{Zn} \mathrm{L}_{23}$. Reference spectra for $\mathrm{CuO}, \mathrm{Cu}_{2} \mathrm{O}, \mathrm{Cu}$ are taken in [19] whereas reference spectra for $\mathrm{Zn}$ and $\mathrm{ZnO}$ are taken in [20] and [21] respectively.

Figure 4: Starting with zinc electrodes. a) TEM overview of $\mathrm{Cu} @ \mathrm{ZnO}$ core-shell NPs. b) High-resolution TEM image showing the $\mathrm{ZnO}$ shell and the $\mathrm{Cu}$ core. c) Identification of hkl planes corresponding to spots 1 to 9 shown in the diffraction pattern d).

Figure 5: Starting with zinc electrodes. a) Electron energy loss spectroscopy near-edge fine structures for the $\mathrm{Cu} \mathrm{L}_{23}$. b) Electron Energy Loss Spectroscopy near-edge fine structures for the $\mathrm{Zn} \mathrm{L} 23$. Reference spectra for $\mathrm{CuO}, \mathrm{Cu}_{2} \mathrm{O}, \mathrm{Cu}$ are taken in [19] whereas reference spectra for $\mathrm{Zn}$ and $\mathrm{ZnO}$ are taken in [20] and [21] respectively.

Figure 6: Starting with zinc electrodes. Identification of weakly abundant $\mathrm{Cu}_{2} \mathrm{O} @ \mathrm{ZnO} \mathrm{NPs}$. Energy-filtered transmission electron microscopy (EFTEM) images of a large $\mathrm{Cu}_{2} \mathrm{O} @ \mathrm{ZnO}$ NP. a) overview. The circled area shows nanopores in the zinc shell. b) Copper map. c) Oxygen map. d) Zinc map. 
Figure 7: a) TEM image showing $\mathrm{Cu}_{2} \mathrm{O} @ \mathrm{ZnO} N P$. b) Corresponding diffraction pattern of $\mathrm{Cu}_{2} \mathrm{O} @ \mathrm{ZnO} \mathrm{NP}$ shown in a). c) Identification of hkl planes corresponding to spots 1 to 7 shown in diffraction pattern $b$ ).

Figure 8: Schematic showing the formation mechanisms of core-shell nanoparticles. a) $\mathrm{Cu}$ NP is wrapped by zinc nanosheet. $\mathrm{Cu} @ \mathrm{ZnO}$ NPs are formed after air exposition. b) Cu NP impacts zinc nanosheet and get fully coated. $\mathrm{Cu} @ \mathrm{ZnO}$ NPs are formed after air exposition. b') $\mathrm{Cu}$ NP impacts zinc nanosheet and get partly coated. $\mathrm{Cu}_{2} \mathrm{O} @ \mathrm{ZnO}$ NPs are formed after air exposition.

Figure 9: Time-resolved optical emission spectra of a) discharges between zinc electrodes immersed in liquid nitrogen loaded in copper (18,000 discharges), b) discharges between copper electrodes immersed in liquid nitrogen loaded in zinc (18,000 discharges). Integration time: $50 \mathrm{~ns}$. All spectra are normalized in intensity.

Figure 10: Time-resolved optical emission spectra recorded at $100 \mathrm{~ns}$ of discharges between copper electrodes immersed in liquid nitrogen loaded either with zinc NPs with zinc electrodes $(18,000$ discharges $)$ or copper and zinc NPs obtained with brass $\left(\mathrm{Cu}_{63} \mathrm{Zn}_{37}\right)$ electrodes (18,000 discharges).

Supplemental Material 1: EDXS line scanning profiles along two $\mathrm{Cu} @ \mathrm{ZnO}$ core-shell nanoparticles synthesized by starting with zinc electrodes.

Supplemental Material 2: Optical emission spectrum recorded at $200 \mathrm{~ns}$ of discharges between copper electrodes immersed in liquid nitrogen loaded in zinc (18,000 discharges). Only N II lines and Cu I lines are detected. No Zn I lines are found. Integration time: 50 ns. The spectrum is normalized in intensity. 


\section{a) COPPER OXIDE}

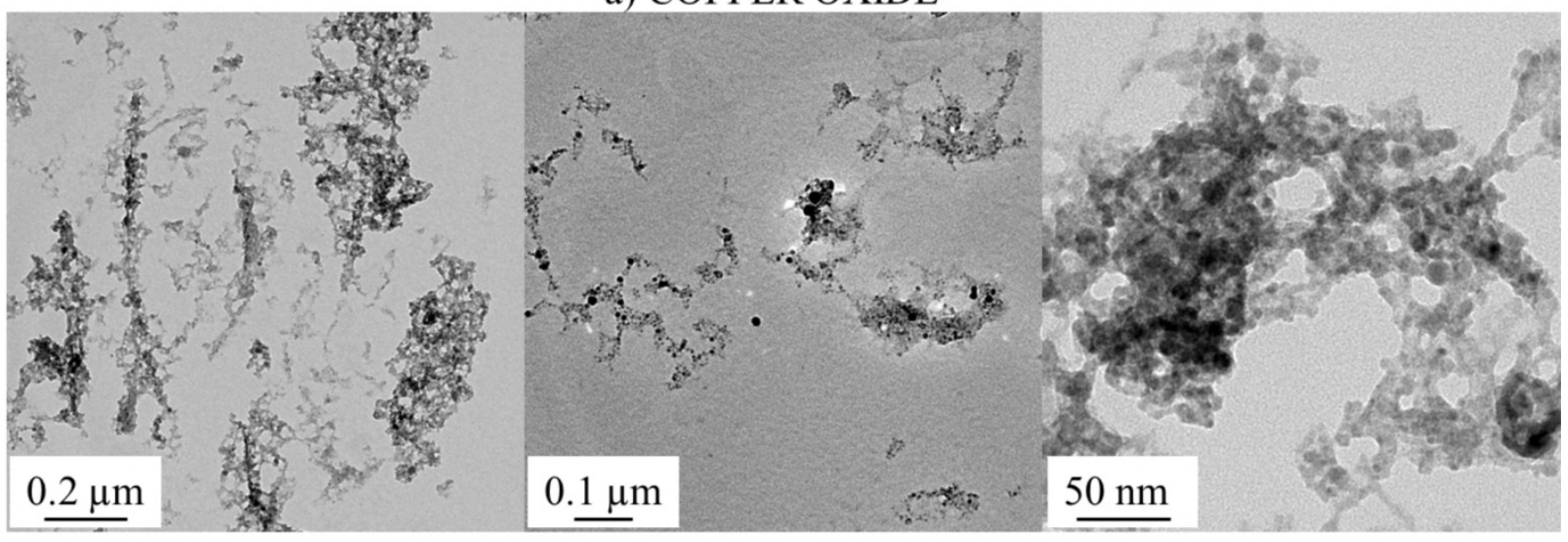

b) ZINC OXIDE

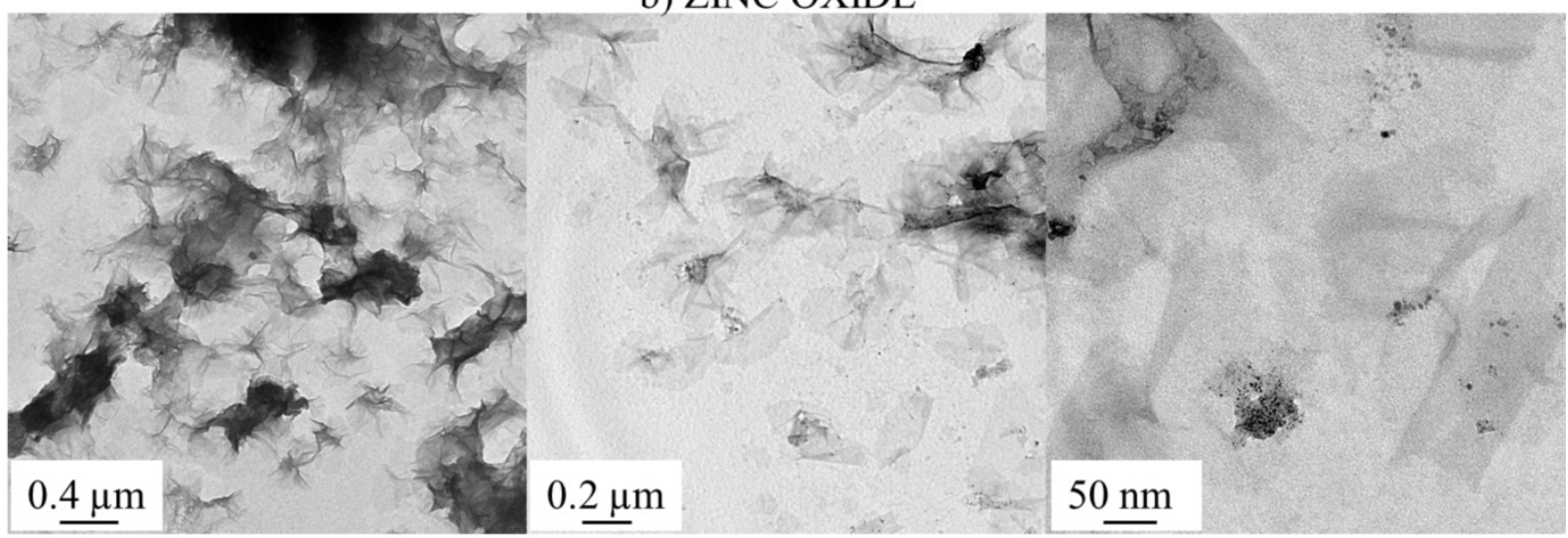

Figure 1: a) Copper oxide $(\mathrm{CuO})$ nanoparticles synthesized between two $\mathrm{Cu}$ electrodes immerged in liquid nitrogen and observed after air exposure at different scales by TEM. b) Zinc oxide $(\mathrm{ZnO})$ sheets and nanoparticles synthesized between two $\mathrm{Zn}$ electrodes immerged in liquid nitrogen and observed after air exposure at different scales by TEM. 

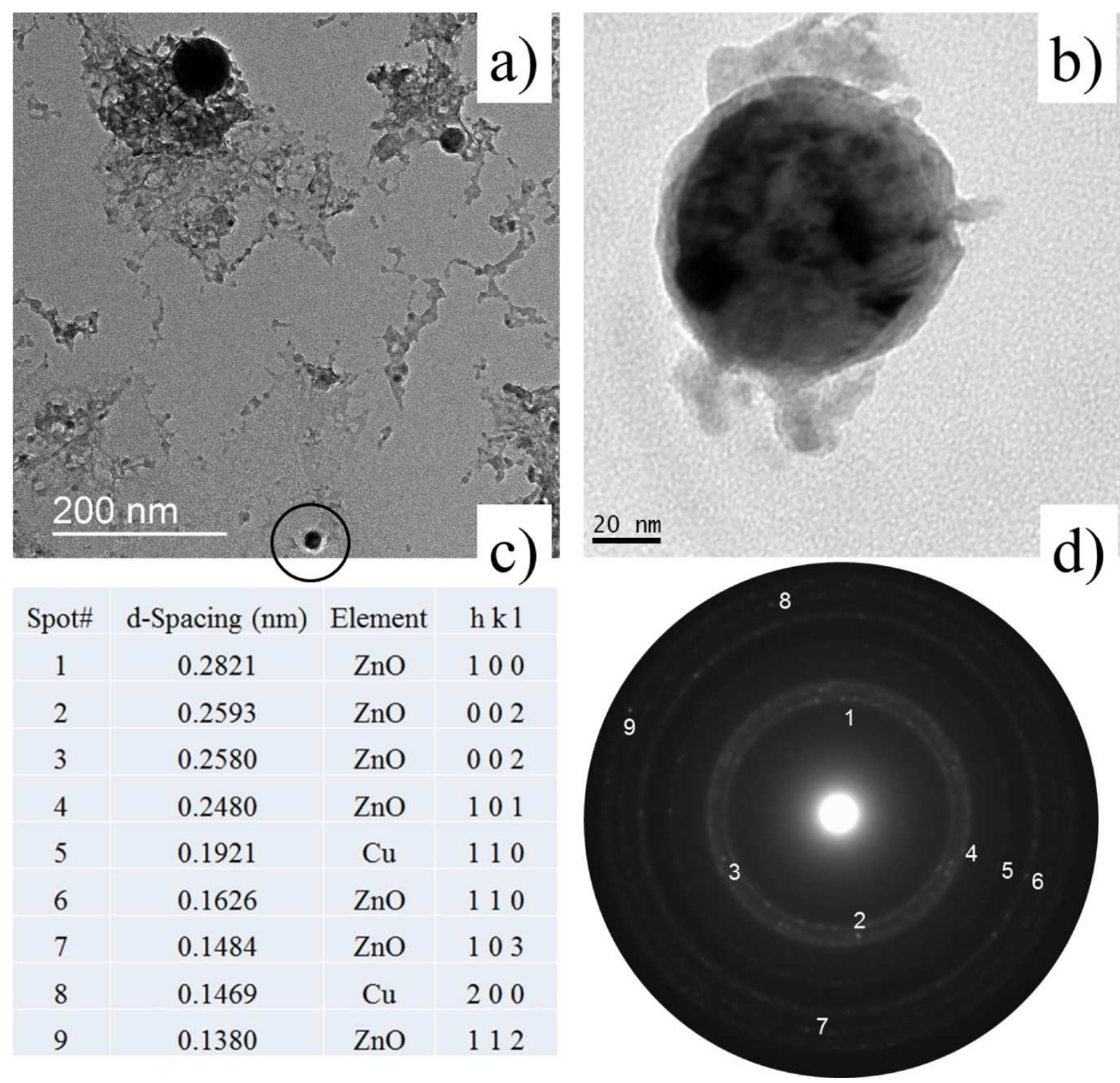

Figure 2: Starting with copper electrodes. a) TEM overview of $\mathrm{Cu} @ \mathrm{ZnO}$ core-shell NPs. b) High-resolution TEM image showing the $\mathrm{ZnO}$ shell and the $\mathrm{Cu}$ core of the particle circled in a). c) Identification of hkl planes corresponding to spots 1 to 9 shown in the diffraction pattern d). 

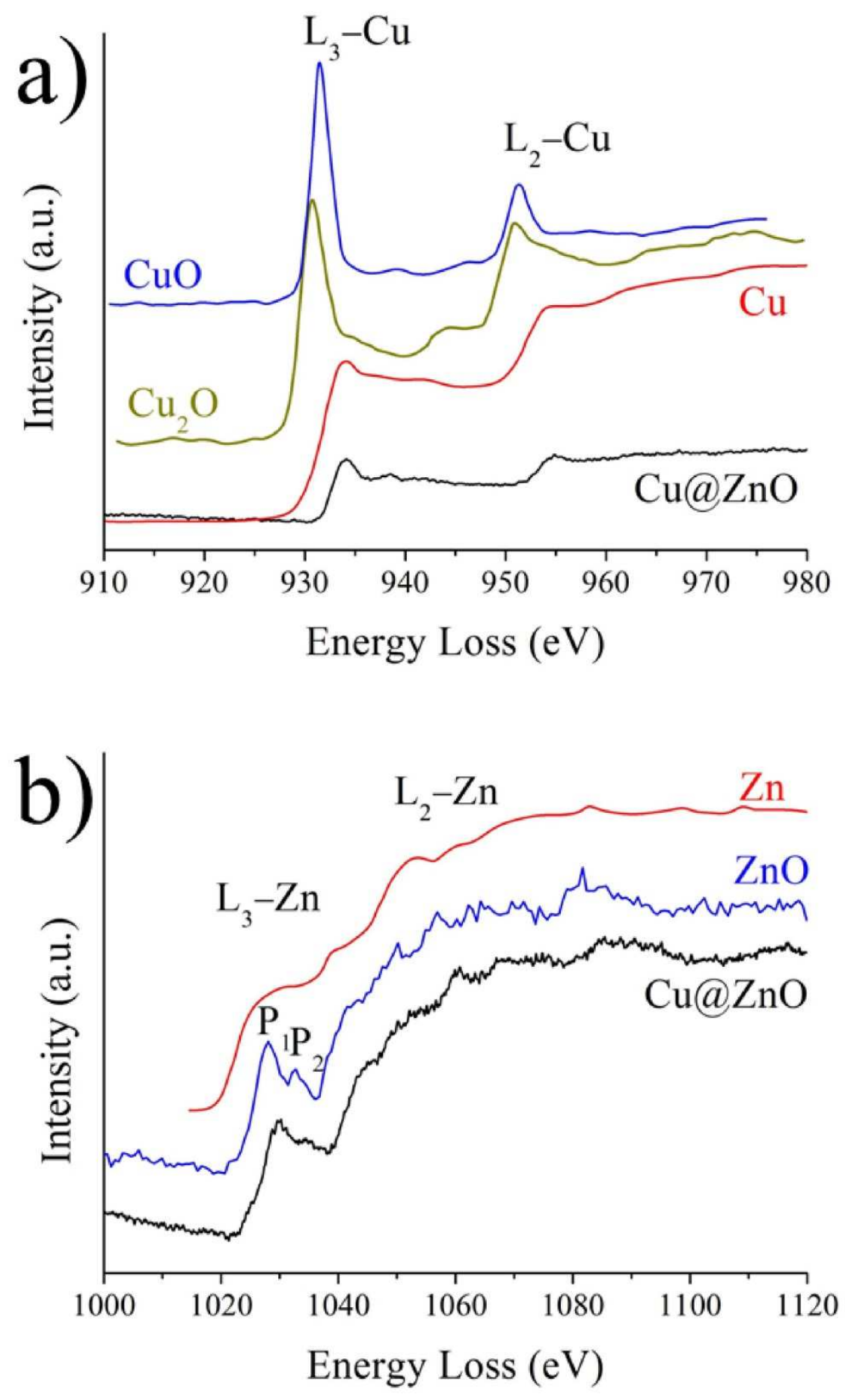

Figure 3: Starting with copper electrodes. a) Electron Energy Loss Spectroscopy near-edge fine structures for the $\mathrm{Cu} \mathrm{L}_{23}$. b) Electron Energy Loss Spectroscopy near-edge fine structures for the $\mathrm{Zn} \mathrm{L} \mathrm{L}_{23}$. Reference spectra for $\mathrm{CuO}, \mathrm{Cu}_{2} \mathrm{O}, \mathrm{Cu}$ are taken in [19] whereas reference spectra for $\mathrm{Zn}$ and $\mathrm{ZnO}$ are taken in [20] and [21] respectively. 


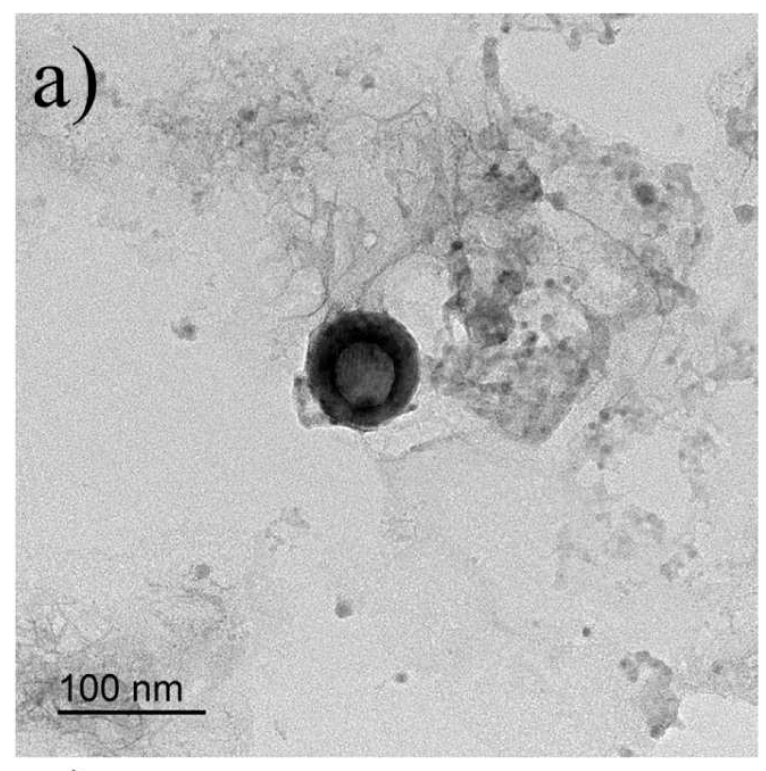

c)

\begin{tabular}{|c|c|c|c|}
\hline Spot\# & d-Spacing (nm) & Element & h k l \\
\hline 1 & 0.2821 & $\mathrm{ZnO}$ & 100 \\
\hline 2 & 0.2593 & $\mathrm{ZnO}$ & 002 \\
\hline 3 & 0.2580 & $\mathrm{ZnO}$ & 002 \\
\hline 4 & 0.2480 & $\mathrm{ZnO}$ & 101 \\
\hline 5 & 0.1921 & $\mathrm{Cu}$ & 110 \\
\hline 6 & 0.1626 & $\mathrm{ZnO}$ & 110 \\
\hline 7 & 0.1484 & $\mathrm{ZnO}$ & 103 \\
\hline 8 & 0.1469 & $\mathrm{Cu}$ & 200 \\
\hline 9 & 0.1380 & $\mathrm{ZnO}$ & 112 \\
\hline
\end{tabular}

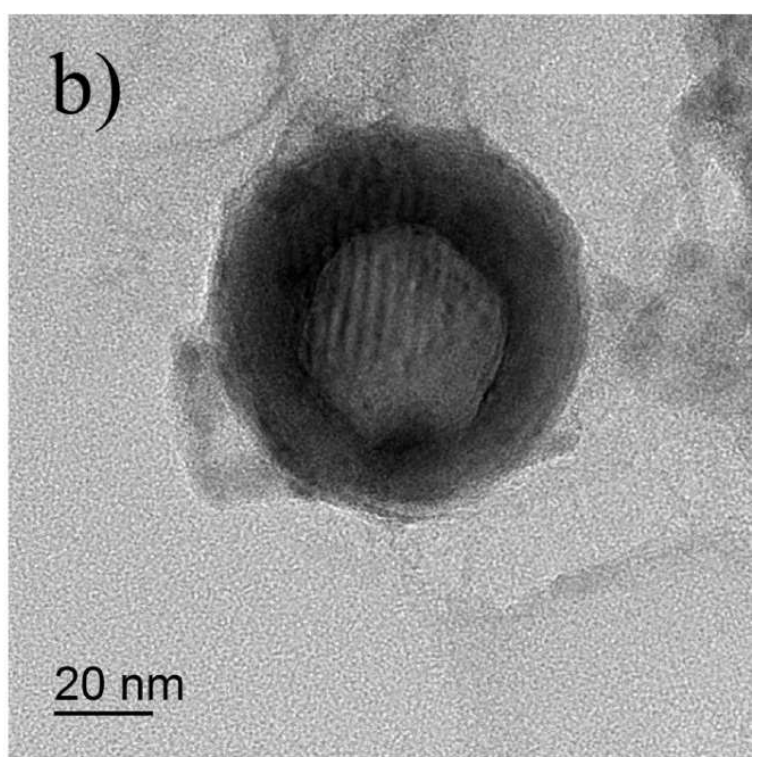

\section{d)}

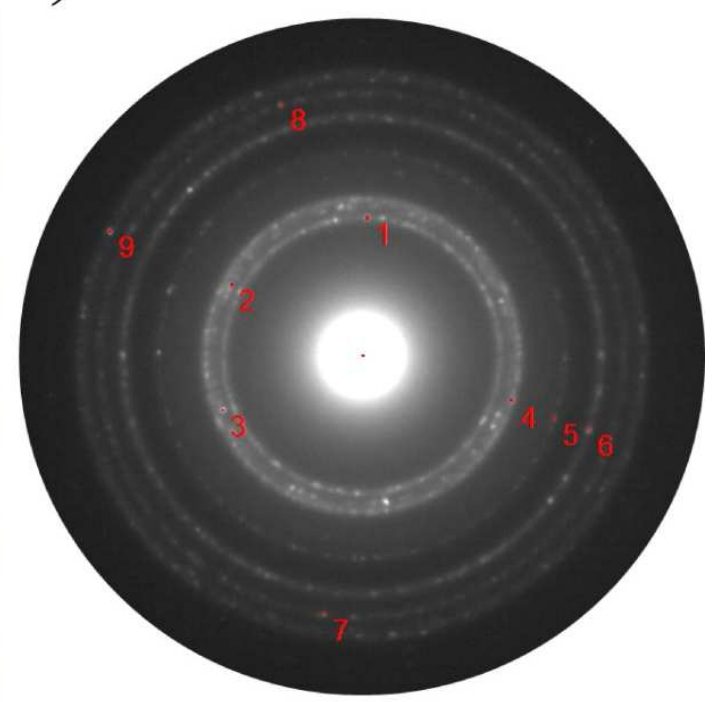

Figure 4: Starting with zinc electrodes. a) TEM overview of $\mathrm{Cu} @ \mathrm{ZnO}$ core-shell NPs. b) High-resolution TEM image showing the $\mathrm{ZnO}$ shell and the $\mathrm{Cu}$ core. c) Identification of hkl planes corresponding to spots 1 to 9 shown in the diffraction pattern d). 

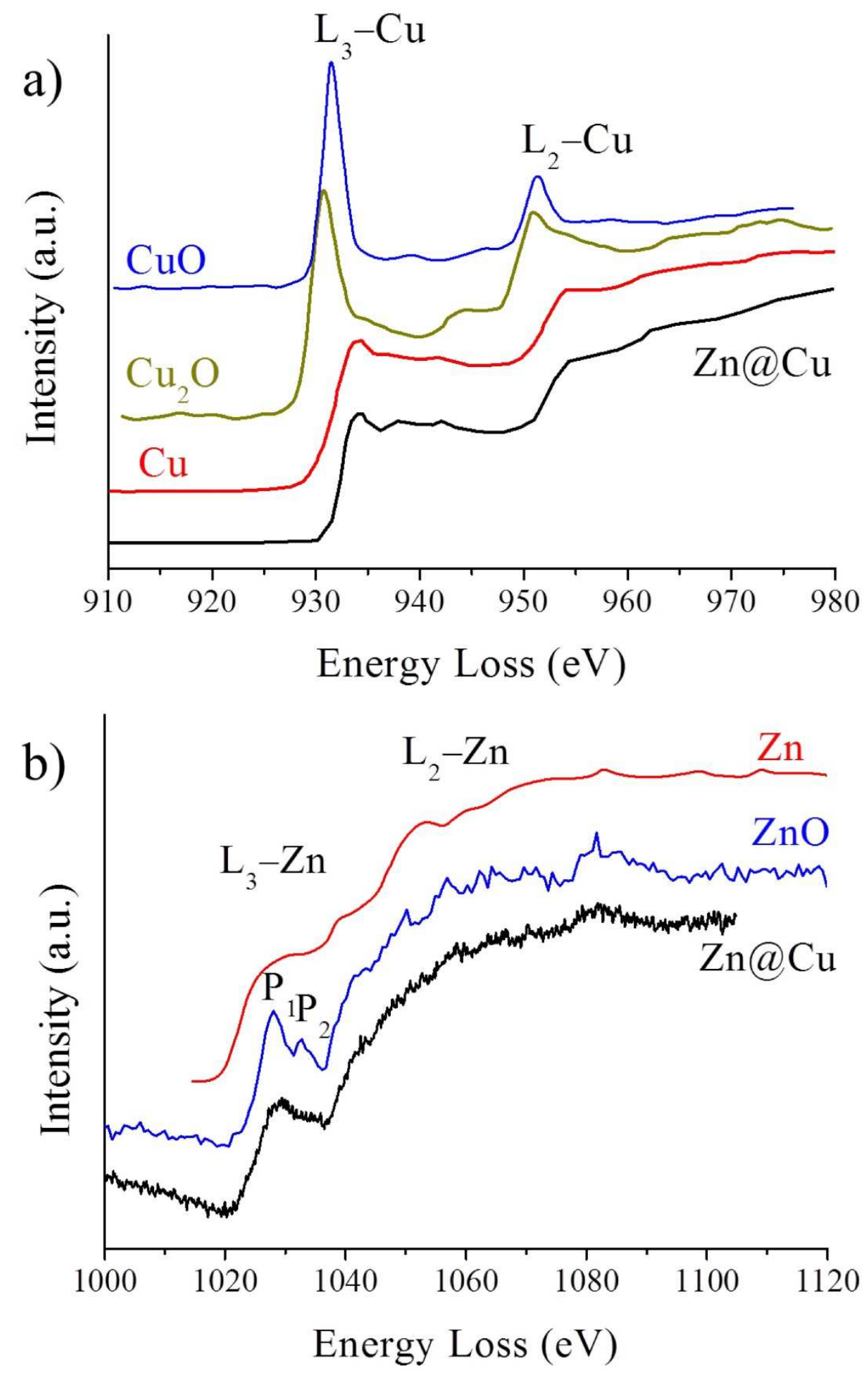

Figure 5: Starting with zinc electrodes. a) Electron Energy Loss Spectroscopy near-edge fine structures for the $\mathrm{Cu} \mathrm{L}_{23}$. b) Electron Energy Loss Spectroscopy near-edge fine structures for the $\mathrm{Zn} \mathrm{L} \mathrm{L}_{23}$. Reference spectra for $\mathrm{CuO}, \mathrm{Cu}_{2} \mathrm{O}, \mathrm{Cu}$ are taken in [19] whereas reference spectra for $\mathrm{Zn}$ and $\mathrm{ZnO}$ are taken in [20] and [21] respectively. 


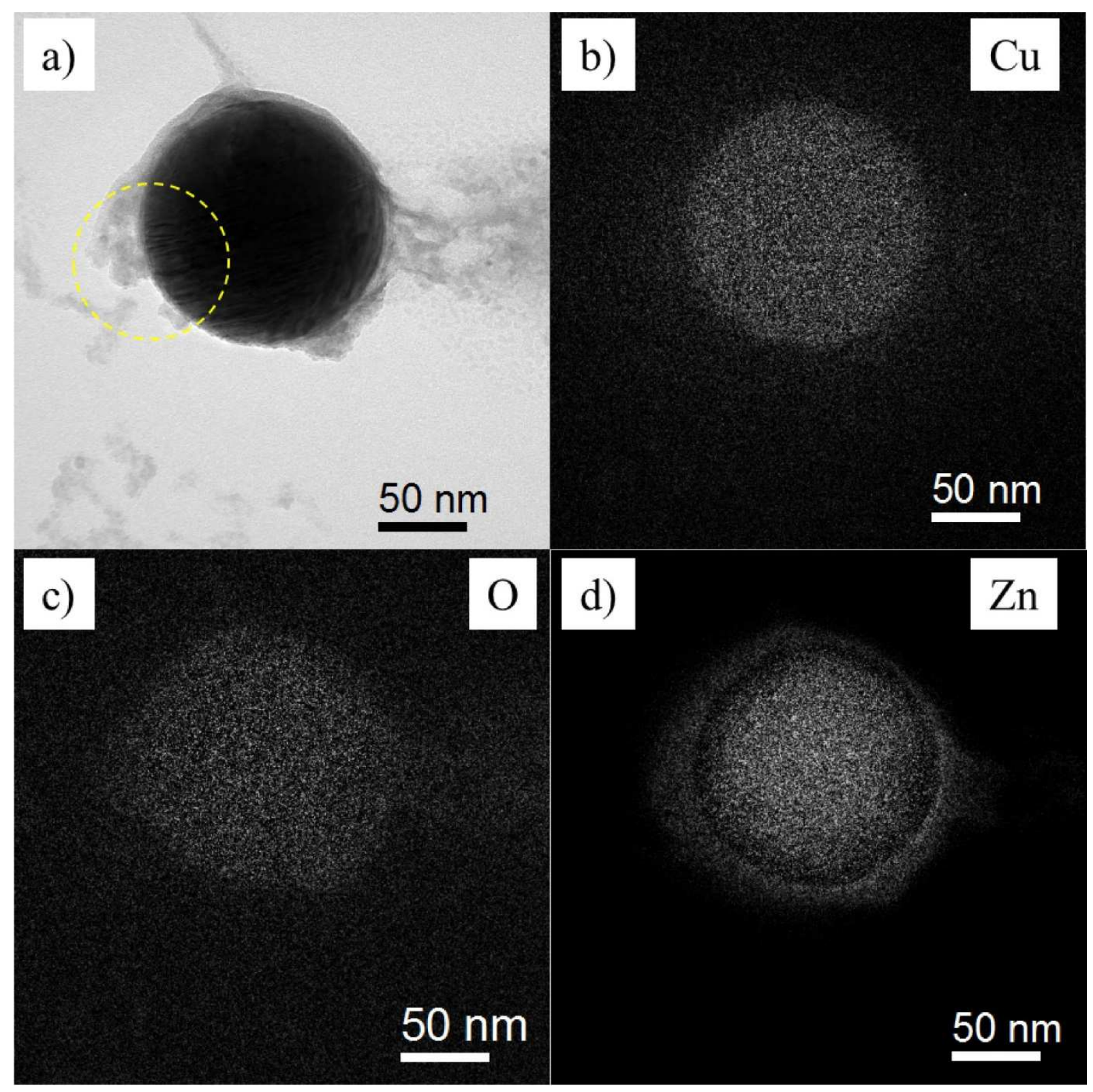

Figure 6: Starting with zinc electrodes. Identification of weakly abundant $\mathrm{Cu}_{2} \mathrm{O} @ \mathrm{ZnO} \mathrm{NPs}$.

Energy-Filtered Transmission Electron Microscopy (EFTEM) images of a large $\mathrm{Cu}_{2} \mathrm{O} @ \mathrm{ZnO}$ NP. a) overview. The circled area shows nanopores in the zinc shell. b) Copper map. c) Oxygen map. d) Zinc map. 

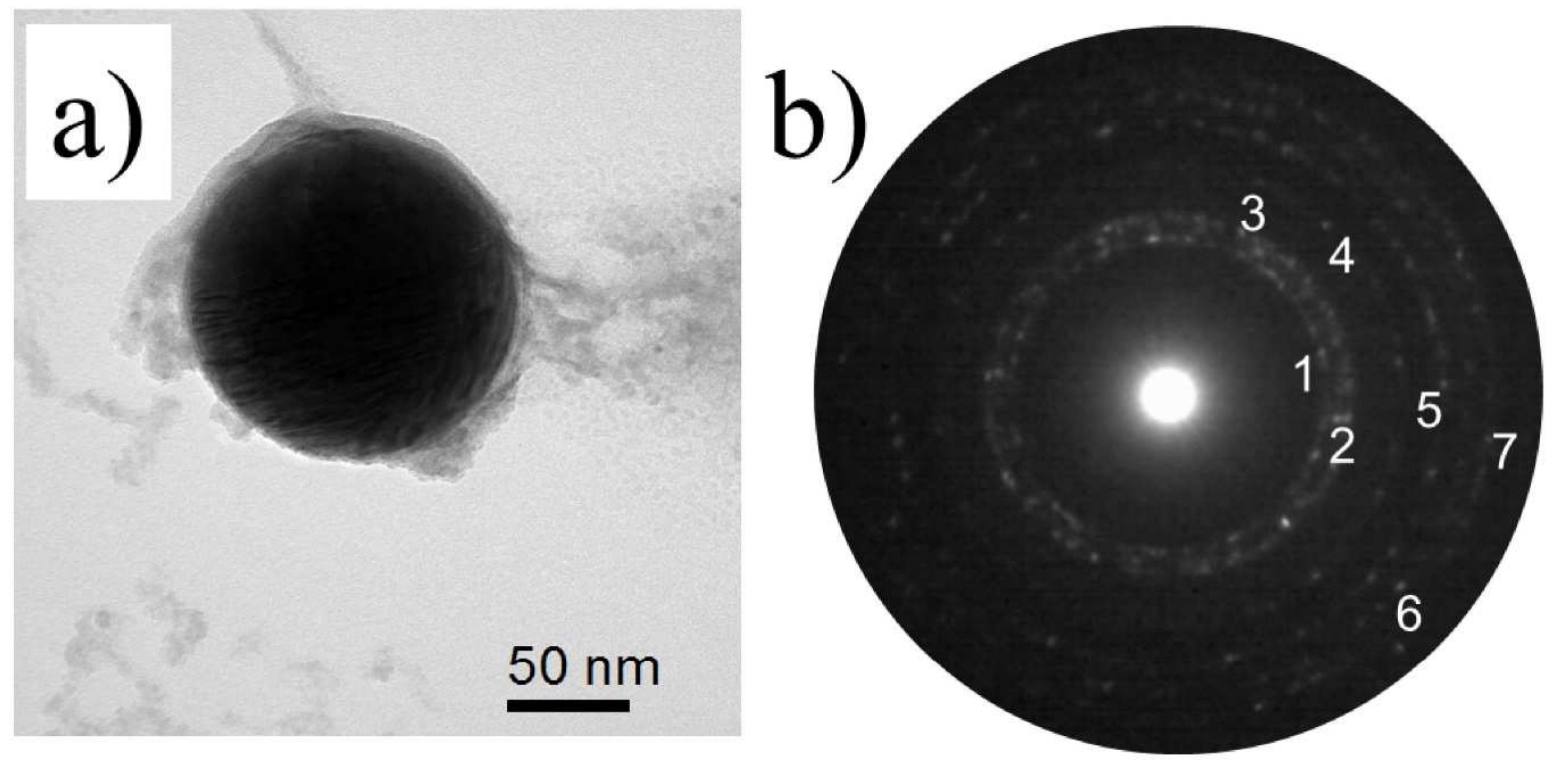

\begin{tabular}{ccccc} 
& Spot\# & $\mathrm{d}$-Spacing $(\mathrm{nm})$ & Element & $\mathrm{h} \mathrm{k} \mathrm{I}$ \\
1 & 0.2834 & $\mathrm{ZnO}$ & 100 \\
\hline 2 & 0.2657 & $\mathrm{ZnO}$ & 002 \\
\hline 3 & 0.2488 & $\mathrm{ZnO} / \mathrm{Cu}_{2} \mathrm{O}$ & $101 / 111$ \\
\hline 4 & 0.1927 & $\mathrm{ZnO}$ & 102 \\
5 & 0.1637 & $\mathrm{ZnO}$ & 110 \\
6 & 0.1501 & $\mathrm{Cu}_{2} \mathrm{O}$ & 220 \\
7 & 0.1398 & $\mathrm{ZnO}$ & 112
\end{tabular}

Figure 7: a) TEM image showing $\mathrm{Cu}_{2} \mathrm{O} @ \mathrm{ZnO}$ NP. b) Corresponding diffraction pattern of $\mathrm{Cu}_{2} \mathrm{O} @ \mathrm{ZnO} \mathrm{NP}$ shown in a). c) Identification of hkl planes corresponding to spots 1 to 7 shown in diffraction pattern $b$ ). 


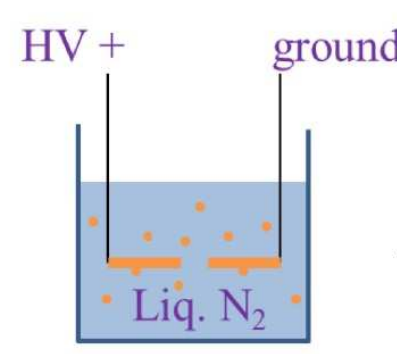

$\mathrm{Cu}$ electrodes 1000 discharges
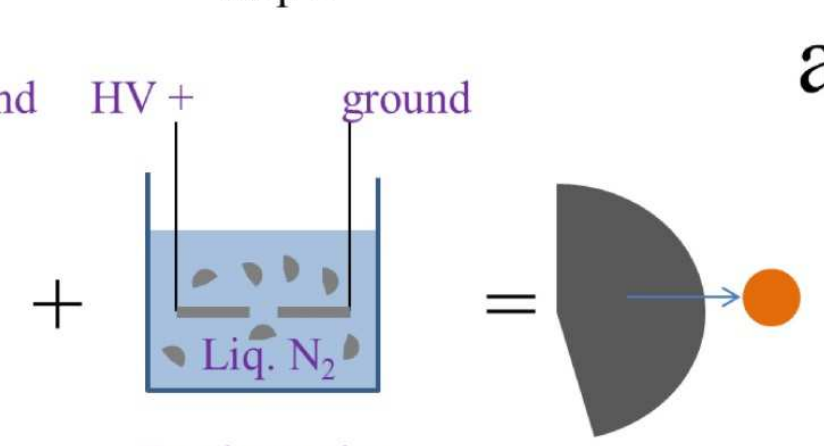

a)
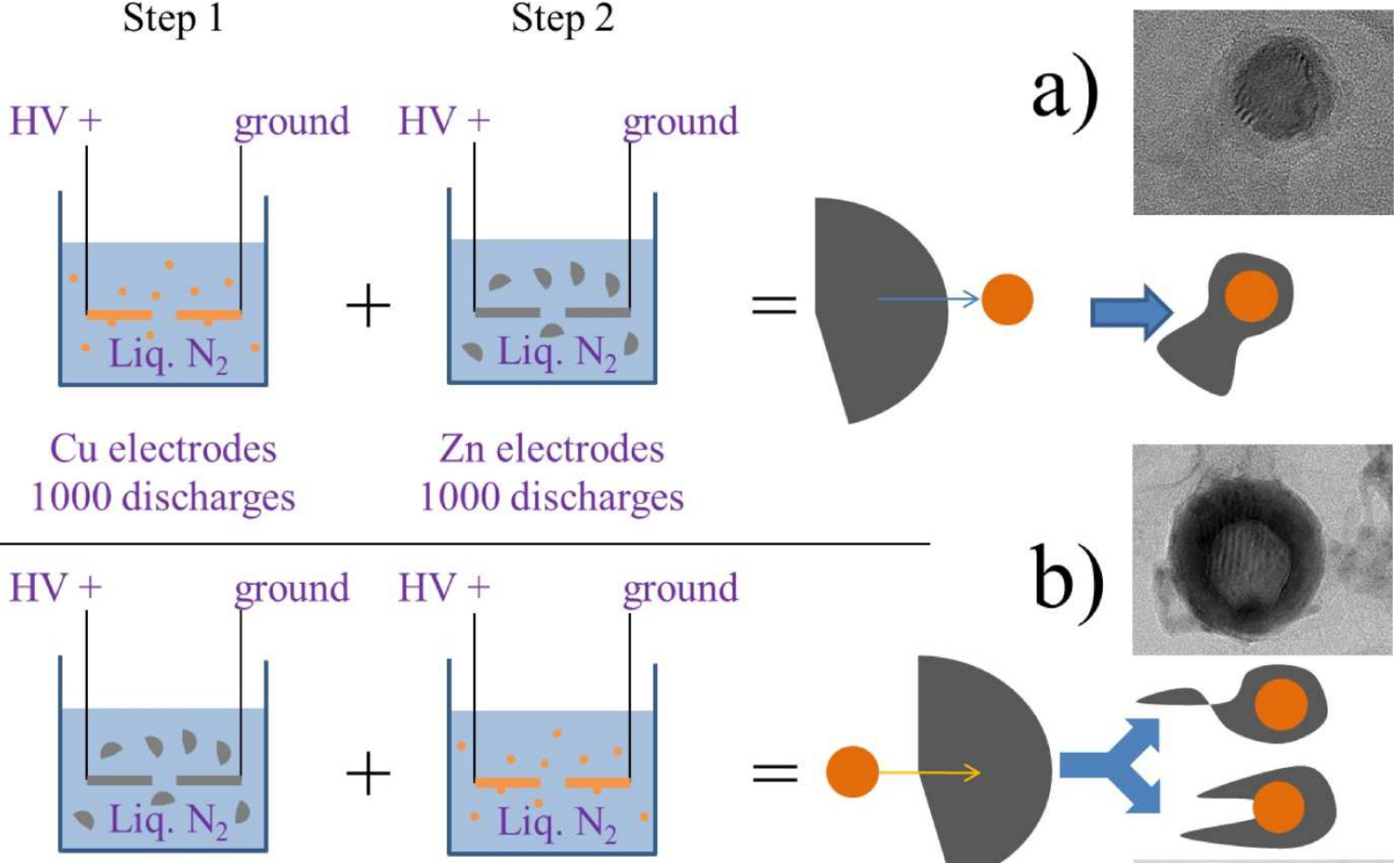

$\mathrm{Zn}$ electrodes 1000 discharges

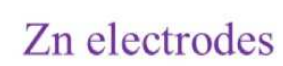

1000 discharges
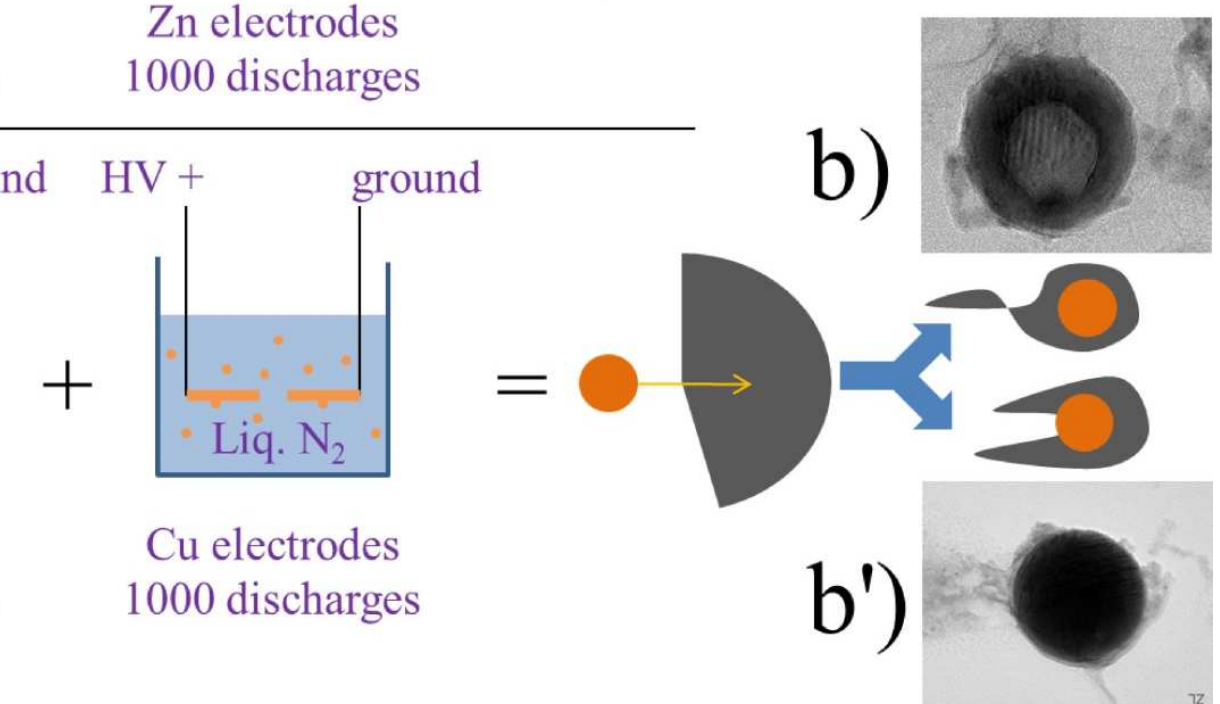

Figure 8: Schematic showing the formation mechanisms of core-shell nanoparticles. a) $\mathrm{Cu}$ $\mathrm{NP}$ is wrapped by zinc nanosheet. $\mathrm{Cu} @ \mathrm{ZnO}$ NPs are formed after air exposition. b) Cu NP impacts zinc nanosheet and get fully coated. $\mathrm{Cu} @ \mathrm{ZnO}$ NPs are formed after air exposition. b') $\mathrm{Cu}$ NP impacts zinc nanosheet and get partly coated. $\mathrm{Cu}_{2} \mathrm{O} @ \mathrm{ZnO}$ NPs are formed after air exposition. 

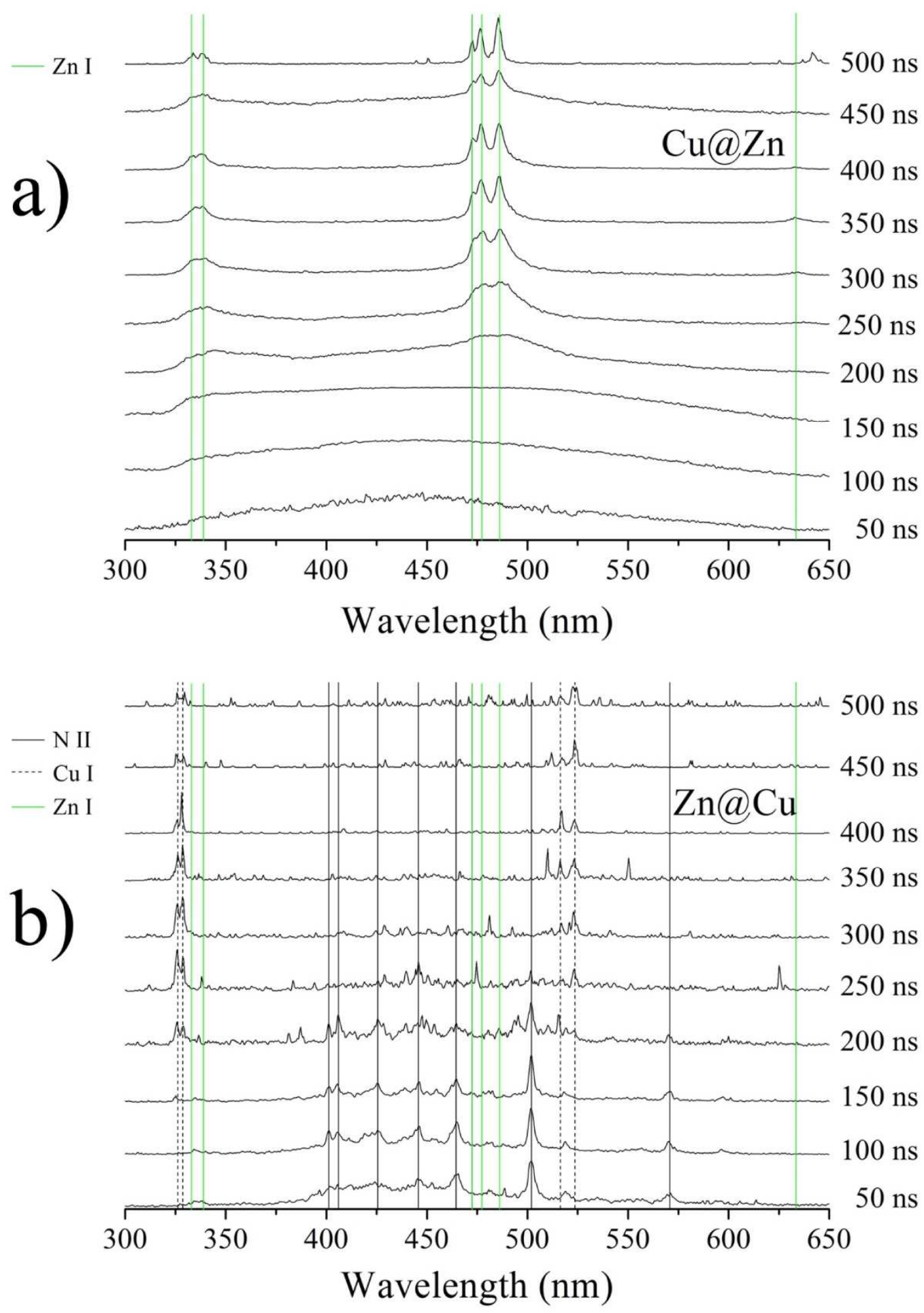

Figure 9: Time-resolved optical emission spectra of a) discharges between zinc electrodes immersed in liquid nitrogen loaded in copper (18,000 discharges), b) discharges between copper electrodes immersed in liquid nitrogen loaded in zinc $(18,0000$ discharges). Integration time: $50 \mathrm{~ns}$. All spectra are normalized in intensity. 


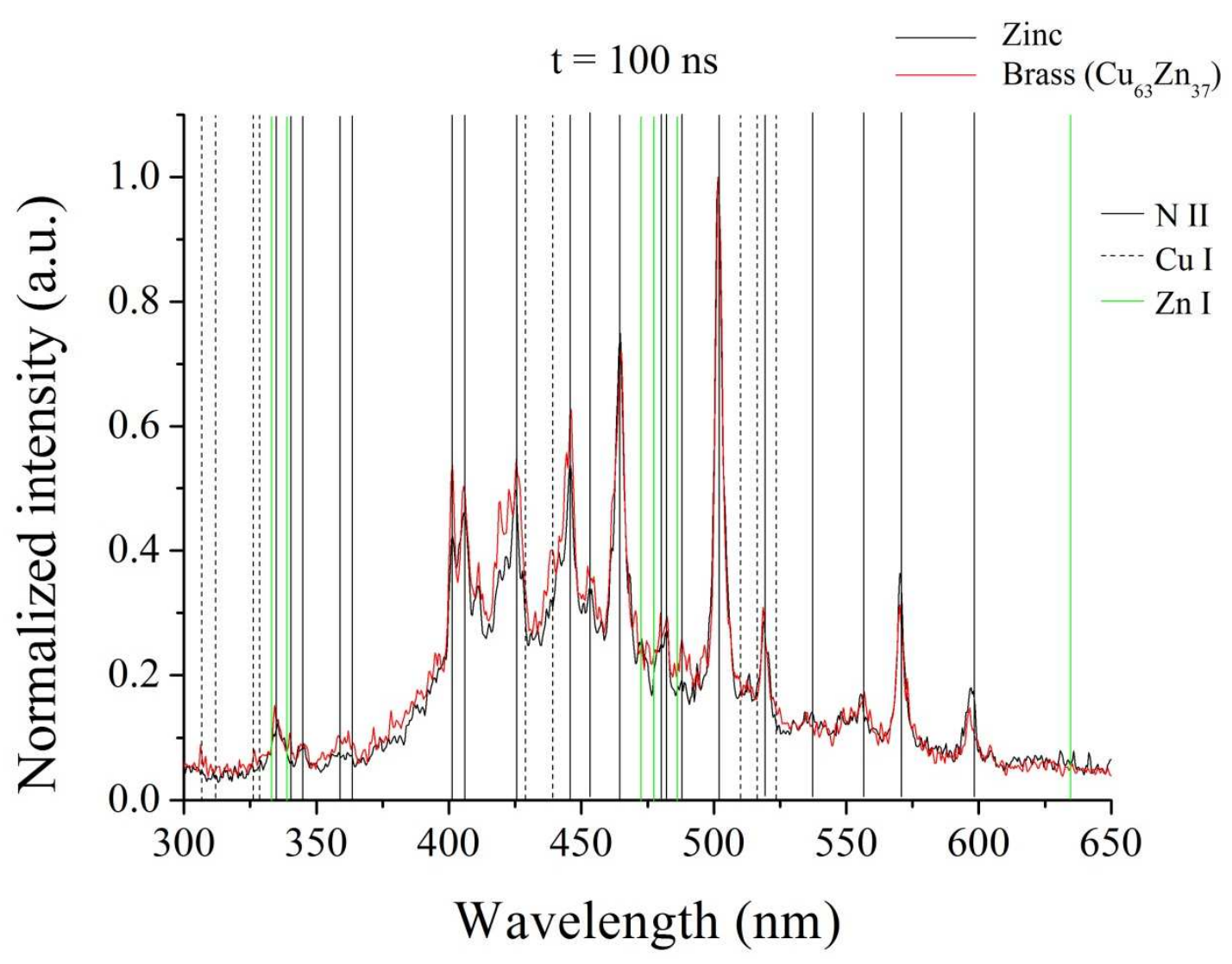

Figure 10: Time-resolved optical emission spectra recorded at 100 ns of discharges between copper electrodes immersed in liquid nitrogen loaded either with zinc NPs with zinc electrodes $(18,000$ discharges $)$ or copper and zinc NPs obtained with brass $\left(\mathrm{Cu}_{63} \mathrm{Zn}_{37}\right)$ electrodes (18,000 discharges). 
SUPPLEMENTAL MATERIAL 1

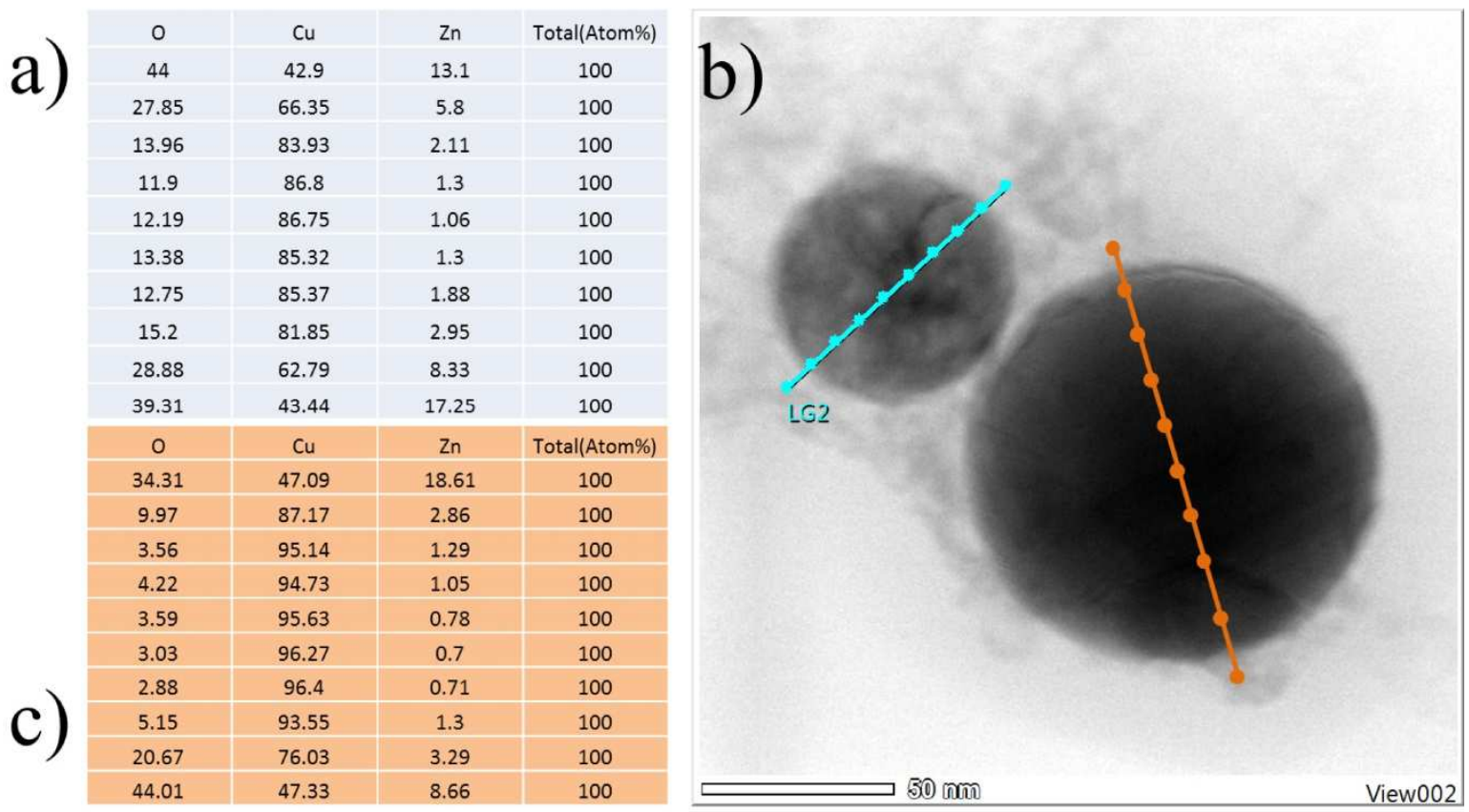

Supplemental Material 1: EDXS line scanning profiles along two $\mathrm{Cu} @ \mathrm{ZnO}$ core-shell nanoparticles synthesized by starting with zinc electrodes. 
SUPPLEMENTAL MATERIAL 2

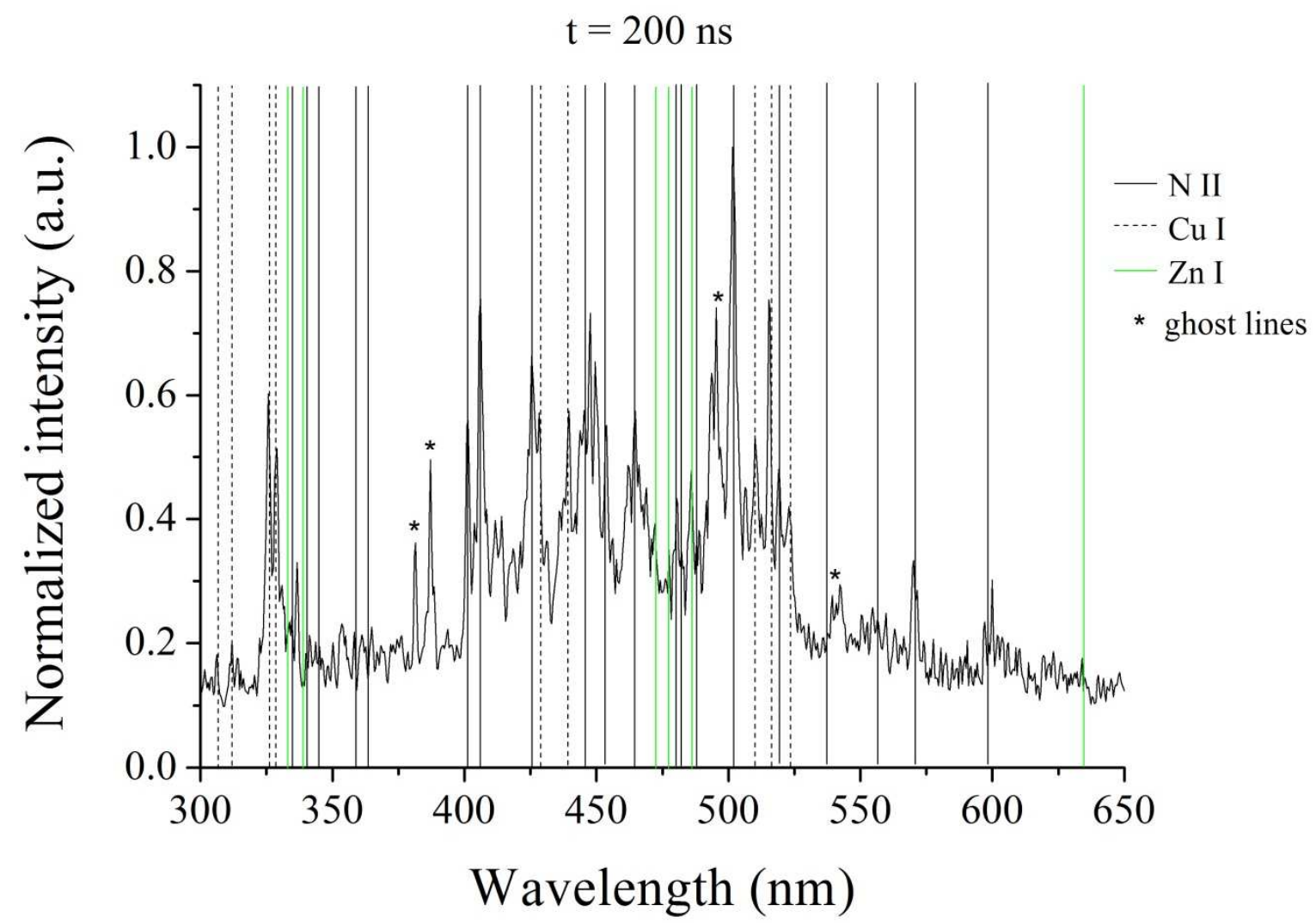

Supplemental Material 2: Optical emission spectrum recorded at $200 \mathrm{~ns}$ of discharges between copper electrodes immersed in liquid nitrogen loaded in zinc (18,000 discharges). Only N II lines and Cu I lines are detected. No Zn I lines are found. Integration time: $50 \mathrm{~ns}$. The spectrum is normalized in intensity. 